\title{
Factors affecting pre-service teachers' participation in asynchronous discussion: The case of Iran
}

\author{
Alice Ebrahimi \\ Alzahra University \\ Esmail Faghih \\ Islamic Azad University (South Tehran Branch) \\ Seyyedeh Susan Marandi \\ Alzahra University
}

\begin{abstract}
This study reports on a qualitative small-scale exploratory study which examined the factors influencing 32 Iranian pre-service language teachers' participation in online asynchronous textbased discussion forums. By adopting a multiple case study design and analysing data gathered through semi-structured interviews and participants' online postings, it was found that access to computers and the Internet or high speed Internet, group size, quality of messages, level of instructor's involvement, grades, interface qualities, participants' personal characteristics and attitudes toward online interactions, as well as familiarity and experience with online discussions influenced participants' level of participation in online discussions. Based on the findings, recommendations are made to help language teacher educators to encourage effective online communication practices in similar educational settings.
\end{abstract}

\section{Introduction}

In recent years, discussion forums, as one of the most widely used asynchronous communication tools, have attracted the attention of teacher educators for a number of reasons. First, due to the anytime/anyplace nature of these tools, they can be easily integrated into both blended and fully online courses to afford student teachers (STs) the opportunity to easily "connect and interact with like-minded peers" to exchange ideas and insights (Hanson-Smith, 2006, p. 300). This property enables the participants to reflect on the content of messages, and review and revise them before posting. Such reflection can promote cognitive as well as critical and higher order thinking skills (Farr \& Riordan, 2015; Nandi, Hamilton, Chang, \& Balbo, 2012).

Second, in addition to cognitive benefits, asynchronous electronic exchanges can afford social benefits by virtue of establishing close student-student and instructor-student relationships which may in turn lead to increased learning outcomes (Groves \& O`Donaghue, 2009; Rienties, 2010). Finally, they can help novice teachers who work at different institutions to discuss aspects of their practice with each other (Romano, 2008).

Although the literature is well documented and vast with regard to the factors affecting student participation in online discussion forums, most existing research has been done in western (US or European) contexts where distance education and discussion forum usage has a long history. Research on this issue in non-Western contexts like Iran is rare. This is due to the fact that despite the affordances ascribed to discussion forums, their implementation in educational settings in Iran is very limited. At the present time, the educational system in Iran is more dominated by traditional methods of teaching and learning, and online education is not prevalent in many universities (Tavakol, 2012). Hence, discussion forums are used rarely and, therefore, little research exists on this issue.

Therefore, this pilot study was carried out to examine Iranian pre-service teachers' perceptions of experiences with online discussions in graduate classes in teaching English as a foreign language (TEFL) master's degree programs to explore in depth the factors that may influence their participation in online discussions. What gives value to this study is the setting and context of the study which adds a new dimension to the existing literature. 
Since there may be differences between educational contexts across the world on a technical or cultural level, it is imperative to conduct more research in non-Western Western contexts to confirm or reject the findings of previous research. The results may promise implications for the effective design of asynchronous communication in online teacher education programs in Iranian and similar settings. The following research question guided the study: What factors may influence the student teachers' participation in (in terms of quantity and quality) online discussions?

\section{Literature review}

In a search for factors that may affect student participation in text-based discussions, several researchers have conducted studies. A comprehensive study which synthesises 110 articles on this issue is one conducted by Hew and Cheung (2012). The researchers grouped the factors that influenced student participation in discussions into 10 emergent categories as follows: not seeing the need for online discussion; behaviour of instructor or other participants; personality traits; difficulty in keeping up with the discussion; not knowing what to contribute; exhibiting surface level thinking; exhibiting low-level knowledge construction; technical aspects; lack of time; and risk of being misunderstood. The findings of most other researchers can be classified into one or more of these categories.

For example, Yukselturk (2010) reported on a study that examined 196 students' participation in discussion forums and found the following reasons for students' low levels of interaction in course discussion: students having different responsibilities and various occupations, the online nature of the course, lack of sufficient interactive activities in the course, students not studying course topics regularly, students' preference for interacting only with participants with a common background. Mann and Talandis (2012) and Chen, Pedersen, and Murphy (2012) reported that perceived overload of information can contribute to some students' low participation. Mason (2011) found that time pressures and lack of motivation were influential in students' participation. Students' low motivation was due to insufficient explanation and encouragement to do the task and inadequate moderator participation. Mokoena (2013) found technical problems, unclear expectations, and insufficient feedback as reasons for poor participation. Küçük, Genç-Kumtepe, and Taşc1 (2010) reported some relationships between students' learning styles and their level of engagement in online discussions; the converger learners appeared to contribute more compared to other learning style groups.

Regarding the impact of some other factors such as instructors' facilitation, group size, and grades, there still exist some controversies. Some researchers advocate a minimum level of instructor involvement. Too much participation on the part of instructors may reduce the amount of student-student interaction and create an unnecessary degree of students' dependence on the teacher (Levitch \& Milheim, 2003). An, Shin, and Lim (2009) maintain that when the instructor's intervention is minimal, students are more inclined to freely express their opinions and thoughts. Also, according to Johnson (2010), when students are the only participants on the discussions, "they feel free to be more honest and open in their responses" and they are more likely to reply to each other in case someone needs assistance (p. 69). In their study examining 400 discussion forums, Mazzolini and Maddison (2007) found that the more the instructors posted, the less frequently students posted and the shorter were the discussion threads.

Contrary to these views, frequent instructor participation is sometimes assumed to encourage student participation. For example, Kearsley (2000) maintains that if the instructor regularly posts messages in the discussion forum, it will increase student involvement and participation in an online course and accompanying discussions. Van den Berg (2012) also emphasises the specific role of the instructors in providing guidance and support in online discussions.

There is also a disagreement on optimal group size in asynchronous discussions. Group size has been long recognised as a factor affecting learners' participation in discussion forums. The research to date reflects no consensus with regard to appropriate group size in online courses. Some researchers recommend the use of smaller discussion groups. For example, Schellens and Valcke (2006) maintain that smaller groups lead to both 
larger proportions of messages as well as higher levels of knowledge construction. In a similar vein, Berry (2008) suggests four to nine students. According to Dennen (2008), as the group size increases, it becomes easier for students to hide and not participate. In contrast, other researchers recommend larger groups of 10-15 (Reonieri, 2006), or even 20 or 25 students (Ko \& Rossen, 2010). They believe that small class sizes could hinder a diversity of views.

Finally, concerning the influence of participation grades, although many researchers advocate their use to promote student contribution, others have questioned their value. On the positive side, Dennen (2005) and Haggerty (2007) maintain that when grades are not awarded for participation in discussion forums, many students post no messages. Also, Ko and Rossen (2010) recommend that discussion participation should account for about $10 \%-40 \%$ of the student's overall grade. However, other researchers like Peters and Hewitt (2010), warn that when discussions are graded, students participate only to meet the course participation requirement and not for genuine collaboration. So, they suggest that either the weight of the participation grade be reduced or eliminated entirely.

In sum, the factors affecting virtual students' participation in online discussions can be classified into three main categories: human-related factors, technology-related factors, and course-related factors. Based on technical and cultural differences, the influence of each category can be different in various educational settings. Considering the fact that the influence of these factors is under-researched in low-tech educational settings like Iran, the present study was conducted to examine the issue.

\section{Method}

\section{Context and participants}

Thirty-two graduate students of TEFL took part in the study. The study extended over the course of two semesters with two different groups of students from three Iranian universities located in the capital city, Tehran. Participants were selected with a non-random purposive sampling method, since they had already been allocated into classes. The first group comprised 20 students from two reputable state universities, that is, Alzahra University (AU) and Sharif University of Technology (SUT). Fifteen STs were from AU and five STs from SUT. The participants' ages in this group ranged from 21 to 51 years $(M=26.70 ; S D=6.27$, mode $=27)$. All participants were attending a joint online course in corpus linguistics (CL) which was an addendum to a face-toface course in computer-assisted language learning (CALL). Unlike the second group who had no previous experience of attending online discussions, STs in this group were attending another discussion group set up by their CALL instructor (the third researcher). So, they were familiar with this type of interaction to some extent.

The second group consisted of 12 students, eight females and four males, from the Islamic Azad University (IAU) who had enrolled in a face-to-face course in "English for Specific Purposes" (ESP). IAU is the world's fourth largest private university. The participants in this group were in the age range of $21-40(M=29.33 ; S D=$ 5.85 , mode $=28$ ). Unlike the first group, nearly all STs in this group had no experience in attending online discussions.

As the demographic data revealed, attending a fully online course was a first experience for all the participants in two groups. Moreover, the topic of the online course, that is, CL, was new for all the participants since TEFL programs in Iran do not include a CL course in their curriculum. With regard to computer literacy and use, most participants had long years of experience in working with computers; they were using computers daily. At the time of the study, $40 \%$ of participants in group one and $75 \%$ in group two were busy teaching.

There were some reasons for the selection of these cases. First, there was an attempt to choose participants who could benefit from a CL course to a great extent; this was done with the intention to encourage STs' active participation in course activities including the discussion forums. Since it is assumed that participants in CALL and ESP courses can benefit considerably from CL (Gavioli, 2005; Partridge, 2006), STs who took these courses 
participated in the study. Next, as the aim of the study was to examine the effects of contextual factors on STs' participation in online interactions, two different educational settings, that is, private versus state universities were used. Moreover, in order to examine the effect of group size as well as participants' previous online discussion experiences on the quality of the interactions, two groups with different numbers of participants (20 versus 12) and varied experiences of attending asynchronous interactions were chosen.

\section{The online course}

Drawing upon Vygotsky's (1978) theory of social constructivism, a course in CL was designed and offered over a 7-week period to the two groups. Central to this theory is the idea that learning happens in social relationships. Thus, to encourage this type of socially constructed learning, interaction through discussion forums was chosen as an essential component of the course. As part of the course requirement, STs were required to share their experiences and reflections about the course materials with their classmates in the discussion forums. The STs' participation in discussions accounted for $30 \%$ of the CL course - since one of the purposes of the study was to examine the STs' perceptions of attending the discussions as a required activity. However, there was no requirement for the number of STs' posts. To encourage rich contributions from the STs, emphasis was placed on the quality of the messages rather than the quantity. The instructor (the first author of the study) acted as a facilitator and guide. Normally, she would start the discussions by posting 2-3 questions after each lesson, although the STs could initiate new topics as well. The STs were encouraged to be the main contributors to the discussions while the instructor's intervention was going to be kept to a minimum. To deliver the courses, a virtual learning environment called Nicenet was used (available at http://www.nicenet.org). It has easy-to-use features for document creation, threaded discussions, and private messaging. To encourage the STs' active participation in the CL course, up to 5 additional bonus points were allocated to participation (both in CALL and ESP courses).

\section{Data collection and analysis}

It is worth noting that this study was part of a larger research project, and only the results related to factors affecting student participation in online discussions are presented here. The main sources of data were postcourse online written interviews; however, to cross-check the results, whenever needed, references are made to online postings. Interview data were analysed using a cross-case analysis approach; since the aim of the analysis was to gain the collective views of the participants regarding each topic, the answers from different STs to common questions were grouped together, and different perspectives on one issue were analysed. Data were coded inductively following the three-Cs approach proposed by Lichtman (2006) and using MaxQDA version 10 - a computer-assisted qualitative data analysis software (CAQDAS). The three Cs stand for codes, categories, and concepts. The units of analysis were thematic units (units of meaning) in a message. In this type of analysis, we assign "a code to a text chunk of any size, as long as that chunk represents a single theme or issue of relevance to our research question(s)" (Zhang \& Wildemuth, 2009, p. 310).

To establish dependability of the study, the first author (who was also the instructor of the CL courses) coded $30 \%$ of the data and then asked another colleague, who had sufficient experience in conducting qualitative research and data coding, to code the same data. The coding consistency was checked through an assessment of inter-coder agreement using percent agreement index. According to De Wever, Schellens, Valcke, and Van Keer (2006), "percent agreement is the result of the ratio between the number of codes which is agreed upon and the total number (agree + disagree) of codes" (p. 10). The inter-coder reliability was 0.85 . After discussing the points of disagreement, the first coder continued the coding procedure. To ensure consistency of analysis, a code-recode approach was employed. Having performed the initial coding, the same researcher recoded the same data after an interval of 3 months, which yielded $90 \%$ consistency between the first and second content analyses.

Moreover, through constant email correspondence with the STs, data were checked for misunderstanding. While analysing the data, to ensure the trustworthiness of the study, attempts were made to consider the counterexamples (deviant and negative cases) and interpret the STs' perspectives with care and to the extent possible without any bias. In reporting the results, to observe ethics of qualitative research, the participants were given 
numbers instead of their true names. In order to make distinctions between the STs in the two groups, STs in the first group were assigned the numbers 1-20, and STs in the second group were labelled 21-32.

\section{Results}

\section{Participants' level of participation in the discussions}

In all, over 7 weeks, the 21 participants in group one (20 STs + instructor) posted 134 messages in 19 threads, which constituted a corpus of 12,840 words. In the second group, 13 participants (12 STs + instructor) took part in 14 discussion threads and produced 82 messages with 5,167 words. Table 1 shows the contributions of students in the first group, while Table 2 displays participants' postings in the second group.

Table 1

Total students' postings per student in group one

\begin{tabular}{lccccl}
\hline Participants & No. of messages & No. of words & $\begin{array}{c}\text { Mean words } \\
\text { per message }\end{array}$ & $\begin{array}{c}\text { Contribution } \\
\text { in } \%\end{array}$ & Weeks of posts \\
\hline ST 1 & 3 & 256 & 85 & 2 & $1,2,4$ \\
ST 2 & 3 & 361 & 120 & 2.8 & $3,4,6$ \\
ST 3 & 7 & 589 & 84 & 4.6 & $1,2,3$ \\
ST 4 & 3 & 203 & 67 & 1.6 & $1,5,4$ \\
ST 5 & 6 & 651 & 130 & 5 & $3,4,5,6,7$ \\
ST 6 & 9 & 351 & 39 & 2.7 & $1,2,3,4,5,6,7$ \\
ST 7 & 0 & 0 & 0 & 0 & - \\
ST 8 & 3 & 378 & 126 & 3 & 1,2 \\
ST 9 & 8 & 996 & 124 & 7.8 & $1,2,5,6$ \\
ST 10 & 0 & 0 & 0 & 0 & - \\
ST 11 & 884 & 110 & 6.9 & $1,2,3,4,5,6,7$ \\
ST 12 & 3 & 388 & 129 & 3 & 4,6 \\
ST 13 & 1575 & 78 & 12.3 & $1,2,3,4,5,6$ \\
ST 14 & 20 & 2530 & 149 & 19.7 & $1,2,3,4,5,6,7$ \\
ST 15 & 17 & 1035 & 79 & 8 & $1,2,3,4,5,6,7$ \\
ST 16 & 13 & 358 & 128 & 2.8 & 6,7 \\
ST 17 & 3 & 50 & 3.1 & $1,2,4,5,6,7$ \\
ST 18 & 8 & 700 & 85 & 6 & $1,3,4,5,6,7$ \\
ST 19 & 9 & 307 & 77 & 2.4 & $1,2,6$ \\
ST 20 & 4 & 0 & 0 & 0 & - \\
Instructor & 0 & 816 & 102 & 6.3 & $1,2,3,5,6$ \\
\hline Total & 8 & 12,840 & $X=95.82$ & 100 & \\
\hline
\end{tabular}


Table 2

Total students ' postings per student in group two

\begin{tabular}{lccccl}
\hline Participants & No. of messages & No. of words & $\begin{array}{c}\text { Mean words } \\
\text { per message }\end{array}$ & $\begin{array}{c}\text { Contribution } \\
\text { in \% }\end{array}$ & Weeks of posts \\
\hline ST 21 & 13 & 950 & 73 & 18.3 & $1,2,3,4,5,6,7$ \\
ST 22 & 2 & 130 & 65 & 2.5 & 1 \\
ST 23 & 4 & 240 & 60 & 4.5 & $1,2,3$ \\
ST 24 & 3 & 152 & 50 & 3 & 1 \\
ST 25 & 4 & 268 & 67 & 5.2 & $1,2,3$ \\
ST 26 & 2 & 148 & 74 & 2.9 & 6 \\
ST 27 & 10 & 330 & 30 & 6.4 & $1,2,3,4,5,6,7$ \\
ST 28 & 1 & 20 & 20 & 0.4 & 1 \\
ST 29 & 9 & 392 & 43 & 7.5 & $1,2,3,6,7$ \\
ST 30 & 11 & 930 & 85 & 18 & $1,2,4,5,6$ \\
ST 31 & 3 & 67 & 22 & 1.3 & 1,2 \\
ST 32 & 10 & 723 & 72 & 14 & $1,2,3,4,5,6,7$ \\
Instructor & 9 & 827 & 91 & 16 & $1,2,3,4,5,6$ \\
\hline Total & 81 & 5167 & $\bar{X}=54.76$ & 100 & \\
\hline
\end{tabular}

As can be seen, STs took part in the discussions to varying degrees. On average, in group one, there were 6.38 postings per participant with a range of 0-20 postings (three STs were inactive and sent no messages). The highest rate of contribution was for two STs (ST 13 \& ST 14) who made $32 \%$ of the total contributions. In group two, on average, there were 6.30 postings per participant with a range of $1-13$ postings. Two STs (ST $21 \&$ ST 30 ) were very active and contributed the most to the discussions (36.3\% of the total contributions). The rest of the students in the two groups had moderate or low participation.

\section{Factors influencing participants' infrequent contributions}

Interestingly, STs in the two groups cited different causes for their low level of participation. With regard to the first group, limited access to computers and the Internet or high speed Internet were the main causes inhibiting some STs' participation. In this group, three STs did not have computers of their own and were relying on campus computers. This is because as students of a state university, they had come from other provinces and had to stay in dormitories; this had imposed some restrictions on their computer use. For example, ST 12 wrote:

I do not have a computer of my own as I'm coming from Shiraz. I use computers of the campus. So, I can't participate whenever I want. (ST 12)

Also, five participants did not have access to the Internet or were on dial-up connections. It is worth noting that the speed of the Internet in Iran is very low especially with dial-up connections. For example, ST 4 wrote:

I have dial-up internet connection, which has very low speed. Even downloading the course lessons was difficult for me. Most of the time, I got the videos from other classmates. Though I was interested to participate more in the discussions, because of this problem I was unable. (ST 4)

However, this was not the case in the second group. As the demographic information showed, all of the STs in this group (except for one) had access to personal computers and an asymmetric digital subscriber line (ADSL) Internet connection. Yet some of them took part in discussions infrequently. No doubt, their low participation was due to other factors. 
First, most of the STs in the second group (75\%) were very busy working and studying simultaneously. This was because they were attending a private university and had to pay tuition. As a result, they put little time and effort into participating in the course. Moreover, nearly half of them were above 30 and had their own families to care for. For example, one of them wrote:

Unfortunately, I am under invasion of life's troops. I do not know what to do. Sleeping at 4 a.m, waking up at 6 a.m teaching from 8 am to $10: 10$ p.m without even a 15 min break. Can you believe it? (ST 26)

Their busy lives had a great influence on both the quantity and quality of the messages they posted. Examining the discussion posts in this group revealed that most of the messages were of low quality as some participants would provide superficial answers to the questions by repeating the materials mentioned in the reading text. Or they made brief answers with no comprehensive responses indicative of sound reflection and deep understanding. They made justifications or inferences without making references to other sources or providing sufficient information. The participants raised only two questions which were left unanswered on the part of other STs. There were also times when some STs provided misleading answers to the questions, which caused the interaction to take on a distorted direction. The instructor had to intervene in the discussions more so as to encourage more reflection and participation on the part of the students; this is evident from the proportion of her contributions to the discussions in this group ( $16 \%$ in group two vs $6.3 \%$ in group one).

Second, the number of students enrolled in the course was small (12); besides, only five were active in the discussions. The rest quit participating almost in the first 3 weeks. In the first group, though there were three people with no posts and some had moderate participations, the large number of the group size (20 STs) prevented the discussions from slowing down. Figure 1 shows the STs' interactions in the two groups during the 7 weeks.

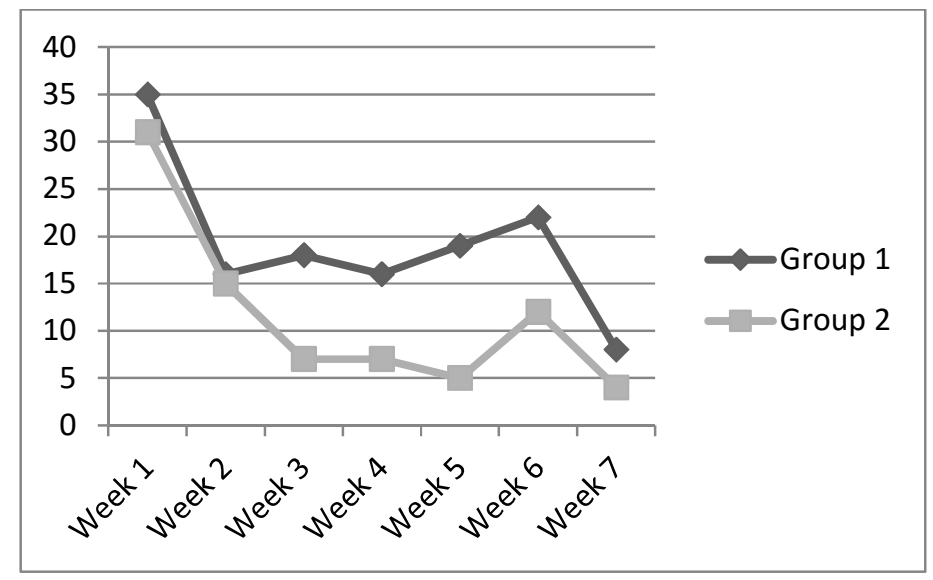

Figure 1. Number of posts per week in the two groups

As can be seen, in the first group, in each week, there were more than 15 posts. So, there were always some people there to discuss and provide guidance and assistance. However, in the second group, low levels of participation led to frustration for some, as is reflected in the words of ST 30:

I do always enjoy sharing, but in this discussion I didn't feel that much sharing among members because they were mostly not there and we were really busy with our projects, reports, proposal, etc. I mean the situation was not a very good one ... (ST 30)

Third, the STs' lack of familiarity with online discussions affected the quantity and quality of messages. Unlike the first group, who had previous experience in attending online discussions, all STs in the second group, except 
for two people, had no previous experience in attending online discussions - whether academic or non-academic. As novice communicants they did not know how to interact successfully. Contrary to the first group who were well capable of starting new threads, the STs in the second group stuck to the prompts posted by the instructor. They were ignorant of others' posts and their answers were at best superficial and, most of the time, repetitions of others' posts or the content of course materials. Regarding this issue ST 25 wrote:

Since not all the students took part in the course and we weren't that familiar with the concepts related to corpora, online courses and discussions and it was just different individuals' understanding of the material, it was some sort of not being as a WHOLE class. (ST 25)

In addition to the reasons mentioned above, other factors were at play. For example, two very smart and knowledgeable students from SUT (ST 1 and ST 8) and one student from IAU (ST 31), participated less in the discussions because they considered them useless and of little added value. In the words of two of them:

Actually, I didn’t attend much. I had not much time. Some people post long messages which are boring to read and take a lot of time. I know that other students are reflecting nonsense for the sake of grades, except Ms. X and Mr. Y. So I didn't bother to waste my time reading fiddle-faddle. Instead, I could explore the issues more in depth myself. (ST 1)

Honestly, I did not have much participation in the discussions. Most of them were not interesting for me. I think maybe it was as a result of the fact that students wanted to receive a good mark just by participation exactly like our CALL class yahoo group. After one or two sessions of reading posts I quit it totally and just read the main lessons that were really useful. (ST 8)

An interesting point about these three STs is their deep understanding of the topics discussed in the course, as reflected in their evaluations of, and reflections on, the weekly lessons and their final course projects. They enjoyed reading the course materials and learned a lot despite infrequent participation in the discussions. In their view, the discussions had low quality, as the others were participating for the sake of gaining grades and thus not contributing valuable information. Reading repetitive responses containing low quality and sometimes erroneous information was both time-consuming and boring for these smart students.

This denotes another important factor effective in the STs' level of participation: STs' personal characteristics. It seems that some smart STs who are capable of exploring things on their own and know how to find answers for their questions - either by searching the Web or other resources - do not always feel the need to attend such discussions. These two STs were very satisfied with the online course and its content; yet, they considered the discussions not very valuable in contributing to their own cognitive development or higher level of thinking and understanding. They felt no need to seek others' viewpoints as they considered them nonsense. ST 1 considered only the postings of his classmates at SUT valuable (Mr. X and Mrs. Y were from SUT). ST 8, also, after reading the posts of two sessions, found them useless. It is also possible that the heterogeneity of the participants in the first group had negative effects on some STs, as this group contained STs from two different universities.

On the other hand, however, two other participants from SUT (ST 14 and ST 11) were very satisfied with the interactions and considered them very influential in their deep understanding of the course topics. It seems possible that their social personality and willingness to communicate with others were influential in their positive views. This is evident from their contributions to the discussions: They took initiative to raise discussion topics, encouraged others with friendly comments, expressed deep affection and support towards others, replied to others' posts promptly and attentively, suggested different perspectives, and provided examples.

Another issue closely related to this is that simply because of their type of personality some STs (six) did not like to interact virtually; they preferred face-to-face interactions which gave them the chance to express their feelings and attitudes more freely. ST 31 was one of these people. She wrote: 
Reading others' opinions is not only time consuming but also boring. I like to see people and their reactions when interacting with them. There are things that you can't say online (feelings and attitudes). I think it would be much better if the class were face-to-face. (ST 31)

Another important factor is the beliefs and attitudes of the STs regarding the interactions. One of the STs was of the opinion that attending the discussions prevented him from experiencing things on his own. He considered the discussion forums useful for lazy people who were seeking for ready-made answers. He wrote:

They are useful when I am too lazy to do things myself. I take the view that we can do everything ourselves if we just try. In forums, some geeks help us and prevent us to experience ourselves. (ST 28)

And in four cases, STs, especially those with dial-up connections, saw no need to attend the discussions, as they could communicate with their classmates face-to face. This implies that STs should see some relationship between using online discussions and their needs; when they see each other every day, they wonder: Why hold discussions online? As one student expressed:

Considering the fact that we are classmates and we can hold these discussions face-to-face, what's the point in using a mailing list when lots of us, including me, have problems accessing a decent internet connection? (ST 17)

Finally, two STs expressed that forum features were influential in their level of participation; they viewed the interface used for discussions as being too simple with no attractions. Moreover, unlike some platforms that automatically send emails to users to inform them of the new messages, Nicenet has no provisions for alerting the STs to the new posts. When STs are immediately aware of new posts, they may be encouraged to participate more.

\section{The influence of grading of the discussion postings on STs' participation}

To find out what really motivated the STs to participate in the discussions, the STs were asked about their intentions for attending the discussions and whether or not they participated for the purpose of their grades. Of 20 STs answering the question, four $(20 \%)$ confessed that they took part in the discussions for the sake of grades because either they did not have much time or did not like interactions on the Web. Eight students (40\%) stated that, initially, their motivation for attending was to receive grades, but later they attended for other reasons, such as enjoying the social and community aspects of the forum or obtaining more in-depth understanding of the topics. The eight remaining STs (40\%) said they attended because they enjoyed the interactions. Two related quotations are presented below:

To be completely honest the grade was part of my motivation at first but after participation in a few sessions I really liked the fact that I could freely interact with my fellow classmates and the social and community aspect was my main motivation in later parts of course for taking part in the discussion. (ST 11)

I am interested to learn new things. It is both for learning and for receiving high grade, of course. (ST 21)

\section{Suggestions for improving the interactions}

The last question of the interview sought the STs' suggestions for improving the interactions. Sixteen people provided answers, summarised as follows with the numbers in parentheses indicating the number of times each was mentioned: 
- The Instructor should participate and provide more feedback. (6)

- Once in a while STs should meet the instructor and interact face-to-face. (5)

- It is good to have video-conferencing. (3)

- The interactions continue after the completion of the course. (2)

- The instructor should require a minimum number of posts and replies. (2)

- The instructor should encourage a more critical approach. (1)

Some of the quotes below reflect these suggestions:

I want to see your suggestion/recommendation/opinion/correction ... to our messages in the conferencing part. I think it will be attractive and show me you pay attention to them; I know you read them but you didn't write anything under our message. (ST 32)

I think it's very good to continue this course and the interactions to practice more on the learnt materials. (ST 15)

I think we should visit our classmates and also the instructor once a while to talk to each other. (ST 13)

As can be seen, some STs preferred to visit the instructor, either through video-conferencing or in person; also, they desired to see the instructor's intervention more. It appears that even at this level the STs still feel the need to gain immediate feedback from the instructor to be assured of the correctness of their messages; or it may reflect the STs' need to gain their instructor's approval and attention.

\section{Discussion}

This study suggests the following factors are influential in STs' level of participation in online discussion forums in language teacher education contexts: access to computers and the Internet or high speed Internet, group size, personal characteristics, STs' beliefs and attitudes towards the usefulness of discussions, quality of messages, level of instructor's involvement, interface quality, grades, and STs' prior experience and familiarity with online discussions. The following sections discuss the results with references to previous related studies.

\section{Technological barriers}

One of the findings of this study - rarely mentioned in previous studies - is some participants' (especially those who attend state universities) limited access to computers and the Internet or high speed Internet. It should be admitted that access to decent technology is a must in online education (Luppicini, 2007). If STs are expected to actively participate in discussions, the first necessary condition is the provision of proper technology for them. This finding may suggest that in designing online courses for these groups of students, discussion participation should not be regarded as compulsory and graded.

Another factor related to technical aspects is the interface quality. In line with the findings of this study, other researchers have acknowledged that some features of the platforms used for discussions can have an impact on students' participation (Hummel et al., 2005; Mokoena, 2013). Therefore, if possible, the platforms used should be attractive for the participants and allow them to easily navigate, and edit or delete messages; it is also preferable that the participants be informed of new messages through emails.

\section{Time constraints}

Most participants of this study were studying and working simultaneously; therefore, they were unable to participate fully in discussions. Some researchers' observations also affirm that lack of time and students' busy lives are important factors resulting in infrequent participation of some online adult students (Mason, 2011; Rollag, 2010; Yukselturk, 2010). Time pressures play a significant role in influencing STs' participation in 
Iranian educational contexts because as a result of receiving low salaries, most language STs and teachers in Iran are forced to work long hours at different institutes or schools. Financial issues are among the factors that other Iranian researchers also have mentioned as a crucial factor hindering pre-service teachers' active participation in any educational or professional development program (Moghaddas \& Zakeri, 2012; Sahragard \& Ansaripour, 2014). It seems that more attention should be given to STs and teachers' well-being.

\section{Personal factors}

Another influencing factor was personal characteristics. In this study three very smart STs expressed dissatisfaction with the discussions due to their type of personality. They preferred to study on their own rather than discuss with others because they saw little value in the messages posted by others. This finding is in accord with what Mehlenbacher, Miller, Covington, and Larsen (2000) have concluded: that interactive Web interfaces may hinder reflective learners. The findings of Battalio (2007) also reflect this issue. Two thirds of all the students in his study preferred to work on their own, rather than interact with others. The fact is that online discussion-based courses are not the preferred mode for some STs such as working STs, smart STs, or STs with little inclination to interact virtually. These students feel satisfied with the course syllabus and its content. As an alternative, instructor-led or content-led courses could be offered to these students; in such courses, students do not need to exchange ideas with other classmates as they discuss the issues personally with the instructor. In contrast, for STs with a preference for face-to face interactions, hybrid courses or on-ground courses could be offered.

Related to this issue, STs' beliefs and attitudes towards the usefulness of this type of interaction play an important role. For most STs, online interactions should bring about meaningful, relevant, and useful learning outcomes. If participants find the discussions uninteresting and unattractive, they would not participate actively (Skinner, 2009). Also, consistent with the findings of Yuen et al. (2009), STs' previous experiences with online discussions had an impact on their participation. This suggests that novice participants should be constantly guided by their instructors on the best practices in online discussions.

\section{Grades}

The findings of this study denote that for about $60 \%$ of the STs, receiving grades was a strong incentive for participating in the discussions. Students in Iran are normally concerned about their grades since the educational system puts a great emphasis on them. This finding, to some extent, confirms the results of other studies which put great emphasis on grading the discussions (Haggerty, 2007; Ko \& Rossen, 2010). The results seem promising, since many STs $(40 \%)$ who were not interested in attending the discussions became more interested as the course progressed, indicating how negative views can be replaced by positive ones as a result of pleasant experiences. If, in the very first sessions, participants found the interactions valuable, enjoyable, and contributing to their learning, they would participate more actively.

Of course, although receiving grades may force the participants to participate in discussions, as Peters and Hewitt (2010) warned, students may participate only to meet the course participation requirement and not for genuine collaboration. Awarding grades by no means guarantees the generation of high quality posts. Considering some STs' reluctance to take part in the discussions - whether as a result of limited access to technology or lack of time, interest, or motivation to interact virtually - this study recommends that a small portion of the course grade (maybe 10\%-15\%) be allocated to the participants' online interactions; this way, the disinclined STs, who take part in discussions merely for receiving grades, would feel less under compulsion to post messages. Enforced participation would possibly lead to the generation of low quality messages of little value. It is better to give all STs the opportunity to participate in the discussions according to their individual styles and preferences. As Battalio (2007) suggests, different versions of the same course with varying amounts and style of online interaction should be designed to meet students' needs. 


\section{Group size}

As regards group size, the findings of this study imply that a class of 20 can be a suitable size for promoting fruitful discussions among participants - particularly in teacher education contexts where the participants are busy working and studying simultaneously. It appears that where there are busy participants in an online course with infrequent participation, the number of STs in the group should be large enough to compensate for the inactive STs' low level of participation. A similar observation has been made by other researchers. For example, Ko and Rossen (2010) have maintained that in an online class of 10, students may become discouraged, fatigued, or bored, while in a class of 20 , even with half of the students being inactive, there is the possibility of generating hundreds of messages. Weick (2014) also supports that a student-to-faculty ratio around 20 to 1 allows for better interactions. Reonieri (2006) and Ko and Rossen (2010) advocate the use of larger groups as well.

The result, however, contradicts the results reported by Schellens and Valcke (2006), Levin et al. (2006), Berry (2008), and Dennen (2008) who recommend the use of smaller discussion groups. Various factors can account for this discrepancy, such as the nature of the course and tasks, the type of educational philosophy dominant in the society (teacher-centred vs student-centred), students' motivation, time constraints, and group dynamics. Of course, we should bear in mind that class size is only one factor among the many that may affect student participation. Each online learning community is unique and, therefore, each instructor should decide on the suitable group size.

\section{Instructor involvement}

As the results of this study reveal, the most common suggestion for the improvement of interactions is to have more instructor involvement in the discussions - either through videoconferencing or in person. Since participants of this study had no or little previous knowledge about CL, they felt the need for the instructor's feedback or involvement much more. Sometimes the questions posed in the discussions were highly technical and needed the direct involvement of the instructor. Moreover, STs in Iran are accustomed to teacher-centred classes; thus, they prefer to rely more on teachers to gain knowledge rather than discuss issues with each other (Noora, 2008). Several other researchers have also highlighted the importance of instructor scaffolding as well as face-toface meetings for ensuring group cohesion and facilitating easier communication (Rienties et al., 2012); other researchers have recommended the use of videoconferencing (Giesbers, 2013; Hrastinski, Keller, \& Carlsson, 2010)

Of course, these suggestions are in contradiction with the observations of other researchers (An et al., 2009; Johnson, 2010; Mazzolini \& Maddison, 2007) who recommend having little or no instructor intervention in the discussions. This inconsistency may be attributed to the differences in the subject matter, group dynamics, students' levels of familiarity with online courses and discussions, degree of students' dependence on the teacher. Considering technical problems in Iran such as access to low broadband or dial-up Internet, it appears that the use of videoconferencing or other synchronous communication tools is not feasible for the time being. Khanmesan (2010) also confirms that in Iran "most users connect to the Internet via dial-up services and the price of the Internet is relatively high. Even some universities have problems in their network and do not have high bandwidth" (p. 275). Thus, it seems more possible that instructors intervene in discussions by posting more messages. A good way to do so is to follow what Arend (2009) suggests, "instead of sharing their own views, instructors would question or extend the discussion using a neutral tone" (p. 16). Another option could be making provisions for face-to-face meetings from time to time. Also, as suggested by Rehm (2013), it is possible to continue interaction after course completion.

\section{Concluding remarks}

This study, though small in scope, identified several factors affecting pre-service teachers' interactions in a lowtech non-Western educational setting. As technical barriers play a significant inhibiting role in these contexts, actions should be taken, in the first place, to provide access to technology and technological support in these 
educational settings. Moreover, since most students are new to online communication, instructors should familiarise them with the basics of interaction in virtual environments. Furthermore, because of students' great dependence on teachers, instructors should provide timely and substantive feedback on students' posts. As suggestions for future studies, researchers could explore if the factors discussed here affect STs' participation in similar contexts; or they could explore how the manipulation of each factor may influence participants' interactions. Moreover, considering the continuing disagreements over the issues of optimal group size, grading, and level of instructor involvement, meta-synthesis studies could be conducted to examine how these disagreements can be resolved or explained.

\section{References}

An, H., Shin, S., \& Lim, K. (2009). The effects of different instructor facilitation approaches on students' interactions during asynchronous online discussions. Computers \& Education, 53(3), 749-760. doi:10.1016/j.compedu.2009.04.015

Arend, B. (2009). Encouraging critical thinking in online threaded discussions. The Journal of Educators Online, 6(1), 1-23. Retrieved from http://www.thejeo.com/Archives/Volume6Number1/Arendpaper.pdf

Battalio, J. (2007). Interaction online: A reevaluation. Quarterly Review of Distance Education, 8(4), 339352.

Berry, G. (2008, August). Asynchronous discussions: Best practices. Paper presented at the 24th Annual Conference on Distance Teaching and Learning, Madison, Wisconsin. Retrieved from http://www.uwex.edu/disted/conference/Resource_library/search_detail.cfm?presid=12701

Chen, C. Y., Pedersen, S., \& Murphy, K. L. (2012). The influence of perceived information overload on student participation and knowledge construction in computer-mediated communication. Instructional Science, 40(2), 325-349. doi:10.1007/s11251-011-9179-0

Dennen, V. P. (2005). From message posting to learning dialogues: Factors affecting learner participation in asynchronous discussion. Distance Education, 26(1), 127-148. doi:10.1080/01587910500081376

Dennen, V. P. (2008). Pedagogical lurking: Student engagement in non-posting discussion behavior. Computers in Human Behavior, 24(4), 1624-1633. doi:10.1016/j.chb.2007.06.003

De Wever, B., Schellens, T., Valcke, M., \& Van Keer, H. (2006). Content analysis schemes to analyze transcripts of online asynchronous discussion groups: A review. Computers \& Education, 46(1), 6-28. doi:10.1016/j.compedu.2005.04.005

Farr, F., \& Riordan, E. (2015). Tracing the reflective practices of student teachers in online modes. ReCALL, 27(1), 104-123. doi:10.1017/s0958344014000299

Gavioli, L. (2005). Exploring corpora for ESP learning. Amsterdam: John Benjamins Publishing Company.

Giesbers, B. (2013). Adding eyebrows to CSCL; The combined use of synchronous and asynchronous communication, and the role of motivation in computer-supported collaborative learning (Doctoral dissertation). Maastricht University, The Netherlands.

Groves, M., \& O'Donoghue, J. (2009). Reflections of students in their use of asynchronous online seminars. Journal of Educational Technology \& Society, 12(3), 143-149. Retrieved from http://www.ifets.info/journals/12_3/13.pdf

Haggerty, C. (2007). Students' experiences of the online learning environment: Working toward improvement (Unpublished master's thesis). University of Queensland, Queensland.

Hanson-Smith, E. (2006). Communities of practice for pre-and in-service teacher education. In P. Hubbard, \& M. Levy, (Eds.), Teacher education in CALL (pp. 300-315). Amsterdam: John Benjamins.

Hrastinski, S., Keller, C., \& Carlsson, S. A. (2010). Design exemplars for synchronous e-learning: A design theory approach. Computers \& Education, 55(2), 652-662. doi:10.1016/j.compedu.2010.02.025

Hew, K. F., \& Cheung, W. S. (2012). Student participation in online discussions: Challenges, solutions, and future research. New York, NY: Springer.

Hummel, H. G. K., Tattersall, C., Burgos, D., Brouns, F., Kurvers, H., \& Koper, R. (2005). Facilitating participation: From the EML web site to the learning network for learning design. Interactive Learning Environments, 13(1-2), 55-69. doi:10.1080/10494820500173474 
Johnson, K. J. (2010). Peer to peer: Using the electronic discussion board during student teaching. In J. Yamamoto, J. C. Kush, R. Lombard, \& C. J. Hertzog (Eds.), Technology implementation and teacher education: Reflective models (pp. 60-76). Hershey, PA: IGI Global.

Khanmesan, A. (2010). E-learning in Iran. In U. Demiray (Ed.), Cases on challenges facing e-learning and national development: Institutional studies and practices. (Volume I, pp. 253-278). Turkey: Anadolu University.

Kearsley, G. (2000). Online education: Learning and teaching in cyberspace. Belmont, CA: Wadsworth.

Ko, S. S., \& Rossen, S. (2010). Teaching online: A practical guide (Vol. 3). New York, NY: Routledge.

Küçük, M., Genç-Kumtepe, E., \& Taşc1, D. (2010). Support services and learning styles influencing interaction in asynchronous online discussions. Educational Media International, 47(1), 39-56. doi:10.1080/09523981003654969

Levitch, S., \& Milheim, W. (2003). Transitioning instructor skills to the virtual classroom. Educational Technology, 42(2), 42-46. Retrieved from ERIC database. (EJ663227)

Luppicini, R. (2007). Review of computer mediated communication research for education. Instructional Science, 35(2), 141-185. doi:10.1007/s11251-006-9001-6

Mann, S., \& Talandis, J. (2012). Developing communities of practice at a distance. In L. England, (Ed.), Online language teacher education: TESOL perspectives (pp. 122-136). London: Routledge.

Mason, R. B. (2011). Student engagement with, and participation in, an e-forum. Journal of Educational Technology \& Society, 14(2), 258-268. Retrieved from http://www.ifets.info/journals/14_2/22.pdf

Mazzolini, M., \& Maddison, S. (2007). When to jump in: The role of the instructor in online discussion forums. Computers \& Education, 49(2), 193-213. doi:10.1016/j.compedu.2005.06.011

Mehlenbacher, B., Miller, C. R., Covington, D., \& Larsen, J. S. (2000). Active and interactive learning online: A comparison of Web-based and conventional writing classes. IEEE Transaction on Professional Communication, 43(2), 166-184. doi:10.1109/47.843644

Moghaddas, B., \& Zakeri, J. (2012). English teacher education in Iran. ELT Voices-India, 21(4), 18-32. Retrieved from http://eltvoices.in/Volume2/EVI24/EVI_24_2.pdf

Mokoena, S. (2013). Engagement with and participation in online discussion forums. Turkish Online Journal of Educational Technology, 12(2), 97-105. Retrieved from http://www.tojet.net/volumes/v12i2.pdf

Nandi, D., Hamilton, M., Chang, S., \& Balbo, S. (2012). Evaluating quality in online asynchronous interactions between students and discussion facilitators. Australasian Journal of Educational Technology, 28(4), 684-702. Retrieved from http://ajet.org.au/index.php/AJET/article/view/835

Noora, A. (2008). Iranian undergraduate non-English majors' language learning preferences. GEMA Online Journal of Language Studies, 8(2), 33-44. Retrieved from http:/ejournal.ukm.my/gema/article/view/171

Partridge, J. (2006). Matching language and IT skills: The life-cycle of an MA programme. In P. Hubbard \& M. Levy (Eds.), Teacher education in CALL (pp. 63-79). Amsterdam: John Benjamins.

Peters, V. L., \& Hewitt, J. (2010). An investigation of student practices in asynchronous computer conferencing courses. Computers\& Education, 54(4), 951-961. doi:10.1016/j.compedu.2009.09.030

Reonieri, D. C. (2006). Optimizing the number of students for an effective online discussion board learning experience (Unpublished master's thesis). Thomas Edison State College, Trenton, New Jersey, USA.

Rehm, M. (2013). Unified yet separated: Empirical study on the impact of hierarchical positions within communities of learning. Maastricht: Uitgeverij Boekenplan.

Rienties, B. C. (2010). Understanding social interaction in computer-supported collaborative learning (Doctoral dissertation). Maastricht University, The Netherlands.

Rienties, B., Giesbers, B., Tempelaar, D., Lygo-Baker, S., Segers, M., \& Gijselaers, W. (2012). The role of scaffolding and motivation in CSCL. Computers \& Education, 59(3), 893-906. doi:10.1016/j.compedu.2012.04.010

Rollag, K. (2010). Teaching business cases online through discussion boards: Strategies and best practices. Journal of Management Education, 34(4), 499-526. doi:10.1177/1052562910368940

Romano, M. E. (2008). Online discussion as a potential professional development tool for first-year teachers. Technology, Pedagogy and Education, 17(1), 53-65. doi:10.1080/14759390701847591

Sahragard, R., \& Ansaripour, E. (2014). Demotivating and remotivating factors among MA students of TEFL: An Iranian case. International Journal of Society, Culture \& Language, 2(1), 88-105. Retrieved from http://www.ijscl.net/article_4502_848.html 
Schellens, T., \& Valcke, M. (2006). Fostering knowledge construction in university students through asynchronous discussion groups. Computers and Education, 46(4), 349-370. doi:10.1016/j.compedu.2004.07.010

Skinner, E. (2009). Using community development theory to improve student engagement in online discussion: a case study. Research in Learning Technology, 17(2), 89-100. doi:10.3402/rlt.v17i2.10867

Tavakol, M. (2012). Virtual applications and real problems: Education and higher education in Iran. Procedia-Social and Behavioral Sciences, 67, 297-303. doi:10.1016/j.sbspro.2012.11.332

Van den Berg, G. (2012). Students' perceptions of the role of lecturers in online discussions. Progressio, 34(1), 71-85.

Vygotsky, L. S. (1978). Mind in society: The development of higher psychological processes. Cambridge, MA: Harvard University Press.

Weick, R. (2014, October 17). Online strategy is essential element of education. Grand Rapids Business Journal, 32(42), 15. Retrieved from http://www.grbj.com/articles/80829-online-strategy-is-essentialelement-of-education

Yuen, H. K., Deng, L., Fox, R., \& Tavares, N. J. (2009). Engaging students with online discussion in a blended learning context: issues and implications. In F. L. Wang, J. Fong, L. Zhang, \& V. S. K. Lee (Eds.), Hybrid learning and education (pp. 150-162). Berlin: Springer-Verlag.

Yukselturk, E. (2010). An investigation of factors affecting student participation level in an online discussion forum. Turkish Online Journal of Educational Technology, 9(2), 24-32. Retrieved from http://www.tojet.net/articles/v9i2/923.pdf

Zhang, Y., \& Wildemuth, B. M. (2009). Qualitative analysis of content. In B. Wildemuth (Ed.), Applications of social research methods to questions in information and library science (pp. 308-319). Westport, CT: Libraries Unlimited.

Corresponding author: Alice Ebrahimi, aebrahimi09@gmail.com

Australasian Journal of Educational Technology (C) 2016.

Please cite as: Ebrahimi, A., Faghih, E., \& Marandi, S. S. (2016). Factors affecting pre-service teachers' participation in asynchronous discussion: The case of Iran. Australasian Journal of Educational Technology, 32(2), 115-129. 